\title{
Gold and Gold Alloy Reference Materials for XRF Analysis
}

\author{
Wieslaw Stankiewicz and Barbara Bolibrzuch \\ Institute of Non-Ferrous Metals, ul Sowinskiego 5, 44-101 Gliwice, Poland \\ and Milosz Marczak \\ Polish State Mint SA, ul Pereca 21, 00-958 Warsaw, Poland
}

\begin{abstract}
A method for the production of a series of certified gold reference materials is presented. These reference materials are intended for use in the analysis of the elemental composition of gold alloys using a nondestructive X-Ray Florescence (XRF) spectrometry method. The chemical composition of the reference materials covers the complete range of conventional coloured and white carat gold jewellery alloys. The XRF method based on this series of reference materials produces analytical results which are comparable with those obtained when using traditional chemical methods of analysis.
\end{abstract}

Described herein are the results of a project designed to develop certified gold and gold alloy reference materials which was undertaken by the Polish State Mint and the Polish Institute of Non-Ferrous Metals (1). The reference materials are suitable for nondestructive testing and particularly for calibration of wavelength (WD XRF) and energy-dispersive (ED $\mathrm{XRF}$ ) spectrometers. They are particularly useful for the elemental analysis of the compositions of various grades of gold (from 8 to 24 carat) and gold alloys (jewellery, electronic, dental, coinage, etc).

Bearing in mind the price of the precious metals and the need for non-destructive analytical procedures, it was decided to produce the reference materials in the form of thin layers (foils) mounted on a special holder of aluminium alloy (Figure 1).

The foils used were thicker than the so-called 'critical thickness', in which $99.9 \%$ of the XRF radiation is generated, in order to avoid eventually rupturing the excitation radiation through the thin layer of alloy. Since the sample may require polishing after mounting onto the holder it was decided to produce foils of at least double the 'critical thickness' (ie 100 - 200 microns depending on the grade of the alloy). The authors felt the need for this series of gold and gold alloy reference materials because of the lack of availability of such materials on the world market - to date only the Royal Canadian Mint has made a series of fine gold (2) and gold bullion (3) reference materials.

The planned compositions for the gold and gold alloy reference materials is given in Table 1 .

The composition for the Au16 sample was purposely chosen as 99.99 rather than $99.96 \%$. With the exception of zinc, which was introduced as a preformed alloy of its pure constituent metals, high purity metals were used for casting the materials for the standards. Melting and casting were performed in a Balzers induction furnace, Type VSG-002 in an argon atmosphere. The ingots obtained were initially analysed by the Polish State Mint. The ingot was

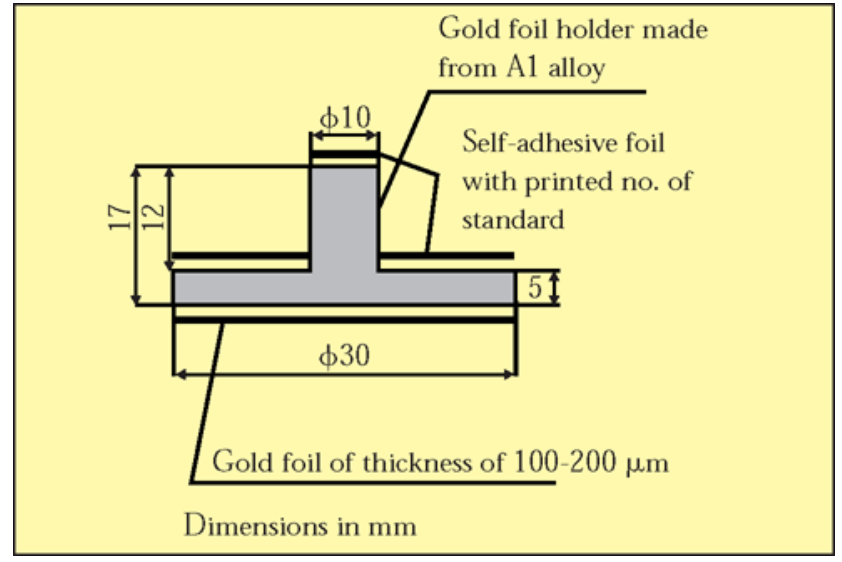

Figure 1 Cross section of gold reference material 
Table 1 Planned compositions for gold and gold alloy reference materials

\begin{tabular}{|c|c|c|c|c|c|c|}
\hline $\begin{array}{c}\text { Sample } \\
\text { No }\end{array}$ & Au \% & $\mathbf{A g} \%$ & $\mathrm{Cu} \%$ & Pd \% & Zn \% & $\mathrm{Ni} \%$ \\
\hline Au 1 & 33.3 & 66.7 & - & - & - & - \\
\hline Au 2 & 33.3 & 44.7 & 22.0 & - & - & - \\
\hline Au 3 & 37.0 & 10.5 & 20.0 & 32.5 & - & - \\
\hline Au 4 & 37.0 & 20.0 & 10.5 & - & - & 32.5 \\
\hline Au 5 & 37.0 & 25.0 & 23.5 & - & 5.5 & 9.0 \\
\hline Au 6 & 50.0 & 12.5 & 12.5 & 25.0 & - & - \\
\hline Au 7 & 57.8 & 27.7 & - & 14.5 & - & - \\
\hline Au 8 & 57.8 & 7.5 & 11.5 & - & 8.7 & 14.5 \\
\hline Au 9 & 57.8 & - & 15.2 & - & 10.0 & 17.0 \\
\hline Au 10 & 75.0 & - & 9.5 & - & 2.5 & 13.0 \\
\hline Au 11 & 75.0 & - & - & 10.0 & - & 15.0 \\
\hline Au 12 & 75.0 & - & - & - & - & 25.0 \\
\hline Au 13 & 91.7 & 3.0 & 5.3 & - & - & - \\
\hline Au 14 & 96.0 & - & 4.0 & - & - & - \\
\hline Au 15 & 98.6 & - & 1.4 & - & - & - \\
\hline Au 16 & 99.99 & - & - & - & - & - \\
\hline
\end{tabular}

annealed in a SOLO 322 strip furnace in a protective atmosphere made from cracked ammonia, peeled on a planing machine to a thickness of $12 \mathrm{~mm}$ and then gradually rolled until the required thickness had been achieved. Discs of diameter $30 \mathrm{~mm}$ were cut from the strips using a die punch on a screw press. The samples could be used for certification after removal of surface impurities from both sides.

The chemical analysis of gold and its alloys is a labour-intensive process because the sample dissolves only slowly and in a complex fashion. If applied to a completed product it will cause damage, and speed of acquisition of the result is frequently important.

The touchstone method, traditionally recognized as the best non-destructive technique to use has a lot of faults, including low accuracy, necessity to possess a complete set of needles, a priori acquaintance of qualitative composition and a high dependence on subjective factors.

Each non-destructive method requires possession of adequate reference materials and some use working standards for some types of materials, but the maximum possible accuracy is obtained when the largest number of standards is available.

\section{DEVELOPMENT AND PRODUCTION OF REFERENCE MATERIALS}

A schematic diagram of the method used to produce the gold and gold alloys is given in Figure 2. The objective was to enable the maximum number of popular grades of gold to be analysed in the most efficient manner and also to include the possibility of analysing other grades of gold. Increased levels of non-homogenity for the more complex alloys and very strong matrix effects were also taken into account, together with the individual needs of the most important producers. This led to the plan represented in Table 1.

The standards Au3-Au12 have been selected from the list of gold jewellery and coinage alloy grades currently made worldwide. Au1, Au2 and Au15 were selected from the Polish Standardization and Measures Daily No 9, March 5th 1974. Au13 (American gold) and Au14 (ducat gold) were added following individual requests from gold producers, following our enquiries.

Preliminary homogeneity evaluations were carried out using a PW1404 Philips XRF Spectrometer. The 


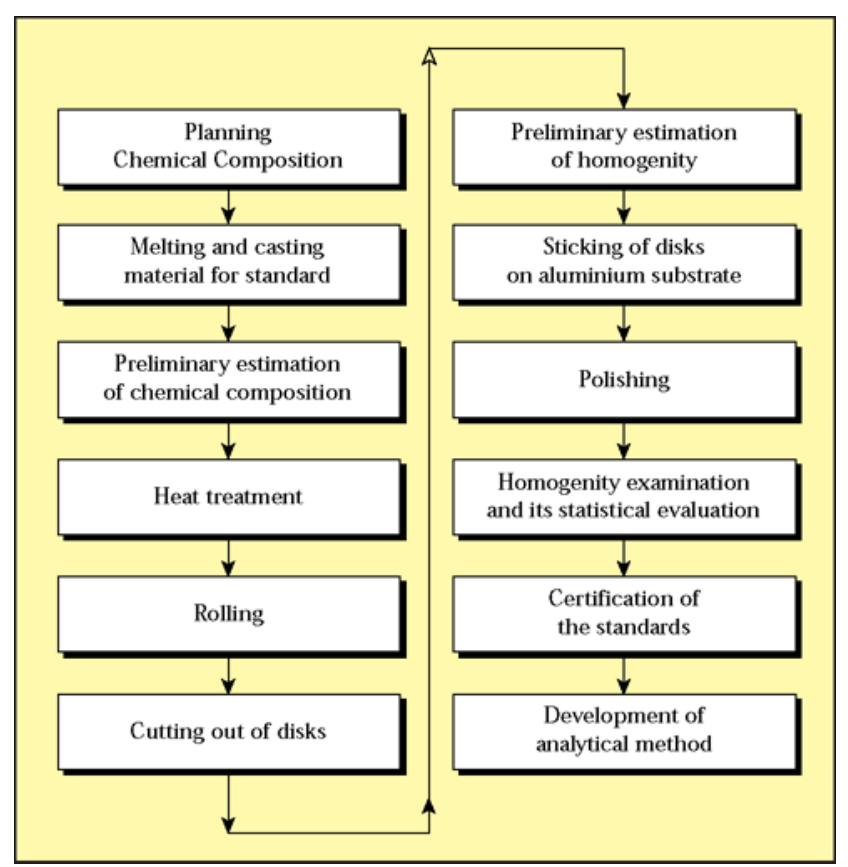

Figure 2 Schematic diagram of development and production of gold and gold alloys reference materials distribution of concentrations of all the alloying constituents (Au, $\mathrm{Ag}, \mathrm{Pd}, \mathrm{Cu}, \mathrm{Zn}$ and $\mathrm{Ni}$ ) were determined by measurements taken from both sides of each disk using ASTM E826-81 and the chemical composition of the materials used. Correlation between the planned and measured compositions allowed progression to successive stages of development and production.

A method for fixing the foils to the aluminium alloy substrate has been developed based on multiple tests. An epoxide adhesive gave a suitably long life and good quality of coupling. Finally, the surface of the standards was polished.

The standards prepared in this way were subjected to statistical examination for homogeneity. The results were obtained via XRF radiation intensity measurements made in four different parts of a given surface of 30 randomly selected discs of each of the 16 standards. This represented $30 \%$ of the reference materials produced. The Snedecor F-test (4) was applied to the statistical calculations. The null hypothesis, indicating that the concentrations of the element examined within the object and between objects do not differ significantly has been verified. The value of $F$ is calculated from Equation (1):

Table 2 Chemical composition of the jewellery gold certified reference materials (gold series)

\begin{tabular}{|c|c|c|c|c|c|c|}
\hline $\begin{array}{c}\text { Sample } \\
\text { No }\end{array}$ & $\mathrm{Au}[\%]$ & $\mathrm{Ag}[\%]$ & $\mathrm{Cu}[\%]$ & $\operatorname{Pd}[\%]$ & $\mathrm{Zn}$ [\%] & $\mathrm{Ni}[\%]$ \\
\hline Au 1 & $33.32 \pm 0.04$ & $65.99 \pm 0.04$ & - & - & - & - \\
\hline Au 2 & $33.35 \pm 0.03$ & $44.65 \pm 0.05$ & $21.98 \pm 0.05$ & - & - & - \\
\hline Au 3 & $37.07 \pm 0.08$ & $10.57 \pm 0.04$ & $20.10 \pm 0.07$ & $32.44 \pm 0.09$ & - & - \\
\hline Au 4 & $37.06 \pm 0.06$ & $20.00 \pm 0.07$ & $10.53 \pm 0.05$ & - & - & $32.43 \pm 0.10$ \\
\hline Au 5 & $37.14 \pm 0.05$ & $25.09 \pm 0.08$ & $23.83 \pm 0.07$ & - & $4.92 \pm 0.05$ & $8.96 \pm 0.06$ \\
\hline Au 6 & $49.99 \pm 0.07$ & $12.54 \pm 0.05$ & $12.53 \pm 0.05$ & $24.96 \pm 0.04$ & - & - \\
\hline Au 7 & $57.88 \pm 0.04$ & $27.68 \pm 0.04$ & - & $14.43 \pm 0.06$ & - & - \\
\hline Au 8 & $57.96 \pm 0.07$ & $7.48 \pm 0.01$ & $11.60 \pm 0.05$ & - & $8.21 \pm 0.05$ & $14.57 \pm 0.07$ \\
\hline Au 9 & $57.81 \pm 0.09$ & - & $15.31 \pm 0.05$ & - & $9.74 \pm 0.06$ & $16.87 \pm 0.09$ \\
\hline $\mathrm{Au} 10$ & $74.83 \pm 0.06$ & - & $9.64 \pm 0.05$ & - & $2.60 \pm 0.03$ & $12.89 \pm 0.04$ \\
\hline Au 11 & $74.95 \pm 0.06$ & - & - & $10.00 \pm 0.05$ & - & $15.05 \pm 0.05$ \\
\hline Au 12 & $74.98 \pm 0.04$ & - & - & - & - & $24.94 \pm 0.06$ \\
\hline Au 13 & $91.67 \pm 0.06$ & $2.76 \pm 0.04$ & $5.28 \pm 0.04$ & - & - & - \\
\hline Au 14 & $96.00 \pm 0.05$ & - & $4.02 \pm 0.03$ & - & - & - \\
\hline Au 15 & $98.60 \pm 0.05$ & - & $1.40 \pm 0.01$ & - & - & - \\
\hline Au 16 & $99.99 \pm 0.002$ & - & - & - & - & - \\
\hline
\end{tabular}




$$
F_{\text {calc }}=\frac{S^{2} 1}{S^{2}{ }_{2}}
$$

Where $S^{2}{ }_{1}$ represents variances corresponding to dispersion of results between samples

and $S_{2}^{2}$ represents variances corresponding to dispersion of results within a sample

The ratios of variances $\left(\mathrm{F}_{\text {calc }}\right)$ were smaller in each case than $F_{\text {tabular, and this confirms homogeneous }}$ distributions of the alloying constituents in all the materials used for standards.

The peripherals remaining after cutting out the discs from the strips were sent to the laboratories used for certification. The average chemical compositions of the jewellery gold reference materials were based on the chemical analyses obtained from the following laboratories:

- Anglo American Platinum Company, Germiston, South Africa

- Anglo American Research Laboratories, Johannesburg, South Africa

- Mintek, Randburg, South Africa

- Genmin Laboratory, Springs, South Africa

- Handy and Harman, Fairfield, Connecticut, USA

- Metalor Refining Corporation, North Attelboro, Massachusetts, USA

- Royal Canadian Mint, Ottawa, Canada

- Rand Refinery, Germiston, South Africa

- Institute of Non-Ferrous Metals, Gliwice, Poland

- Polish State Mint, Warsaw, Poland

Table 3 Analytical parameters of the PW 1404 spectrometer $^{a}$

\begin{tabular}{lccc} 
Element & Analytical Line & $2 \Theta\left[^{\circ}\right]$ & Detector \\
$\mathrm{Au}$ & $\mathrm{L} \alpha$ & 36.960 & $\mathrm{FC}^{1}+\mathrm{SC}^{2}$ \\
$\mathrm{Ag}$ & $\mathrm{K} \alpha$ & 15.970 & $\mathrm{SC}$ \\
$\mathrm{Pd}$ & $\mathrm{K} \alpha$ & 16.720 & $\mathrm{SC}$ \\
$\mathrm{Cu}$ & $\mathrm{K} \alpha$ & 45.025 & $\mathrm{FC}+\mathrm{SC}$ \\
$\mathrm{Zn}$ & $\mathrm{K} \alpha$ & 41.800 & $\mathrm{FC}+\mathrm{SC}$ \\
$\mathrm{Ni}$ & $\mathrm{K} \alpha$ & 48.670 & $\mathrm{FC}$ \\
9) The following remaining parameters were applied while measuring: \\
voltage/intensity of the X-ray tube - $60 \mathrm{kV} / 50 \mathrm{~mA}$ \\
analysing crystal - LiF200 \\
collimator - fine \\
pulse height analyser - lower level 20 \\
\multicolumn{4}{c}{ upper level 80} \\
1) flow proportional counter ${ }^{2}$ ) scintillation counter
\end{tabular}

The following methods were used for the elements, as indicated below:

Au - cupellation, weight

$\mathrm{Ag}$ - potentiometric, weight, ICP

$\mathrm{Cu}$ - ICP, AAS, electrolytic

Pd - ICP, weight

Zn - ICP, weight, AAS

$\mathrm{Ni}$ - weight, ICP, AAS, electrolytic

The final compositions obtained for the jewellery gold reference materials are given in Table 2 .

\section{QUALITY OF THE XRF ANALYSIS RESULTS FROM THE GOLD JEWELLERY ALLOYS AU1 - AU16}

$\mathrm{X}$-ray spectrometry laboratories often need to analyse several grades of jewellery or other gold. The possibility of their analyses being based on one series of standards which could be used for several types of alloys would considerably simplify the calibration procedure, since when alloys of different constituents are analysed strong matrix effects can be taken into account. The matrix effects are the source of the most important systematic errors in XRF spectrometry. The absorption enhancement effects are the most essential components of the matrix effects, and they result predominantly from a differentiated chemical composition in the analysed material.

The very wide range of chemical compositions is covered by the series of reference materials which correspond to the jewellery alloys made most frequently, ie Au (33.32 - 99.99\%), Ag (0 - 66.59\%), $\mathrm{Pd}(0-32.44 \%)$. This investigation was designed to establish whether the percentage of each element could be determined using the XRF technique. The

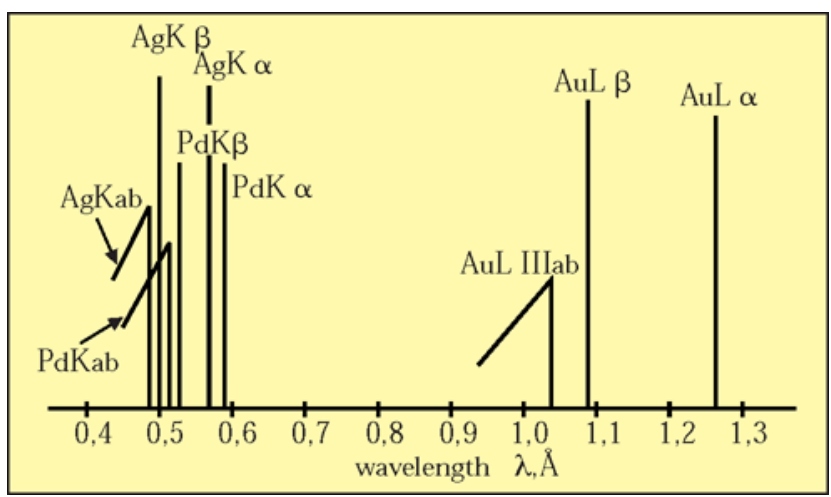

Figure 3 Analytical line and absorption edges of silver, palladium and gold 
Table 4 Correction coefficients ensuring optimum correction of matrix effects

\section{Determined element ' $i$ '}

$\begin{array}{cc}\mathrm{Au} & \mathrm{Ag}, \mathrm{Pd}, \mathrm{Au}, \mathrm{Ni}, \mathrm{Cu} \\ \mathrm{Ag} & \mathrm{Pd}, \mathrm{Ag}, \mathrm{Au}, \mathrm{Ni}, \mathrm{Cu} \\ \mathrm{Pd} & \mathrm{Au} \\ \mathrm{Cu} & \mathrm{Ag}, \mathrm{Pd}, \mathrm{Au} \\ \mathrm{Zn} & \mathrm{Cu} \\ \mathrm{Ni} & \mathrm{Pd}, \mathrm{Au}, \mathrm{Zn}\end{array}$

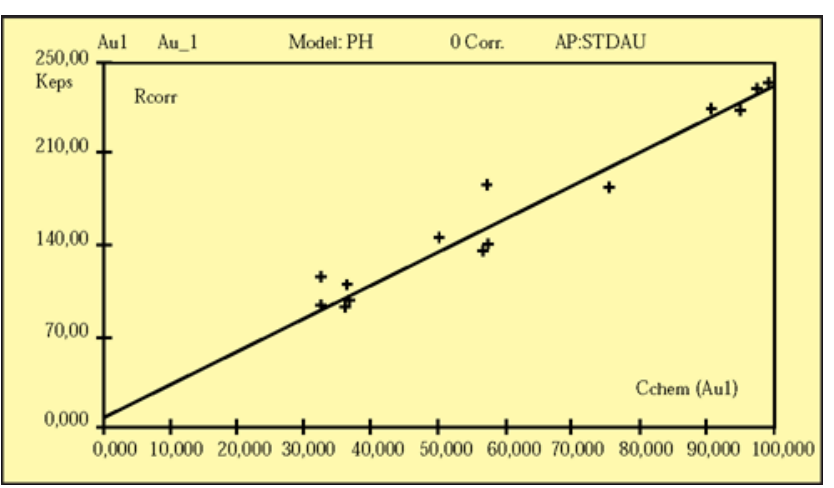

Figure $4 A u L \alpha X$-ray fluorescence intensity vs concentration of gold. Average standard deviation: $S=4.82 \% \mathrm{Au}$

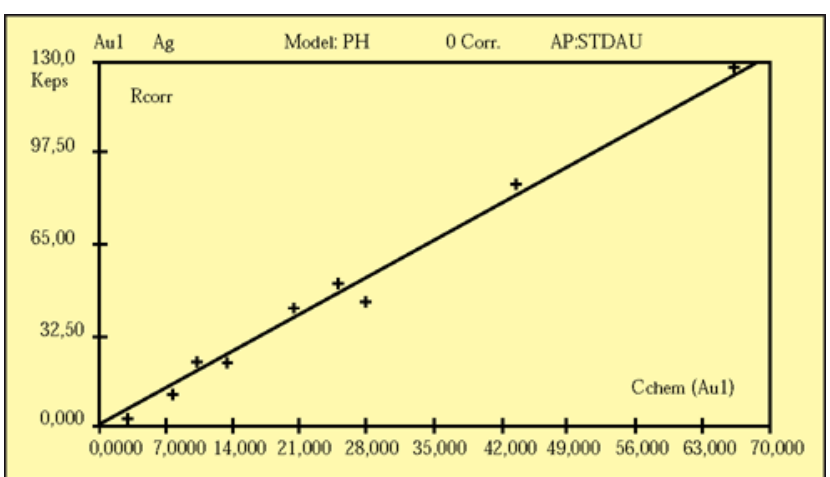

Figure $5 \mathrm{AgK \alpha} X$-ray fluorescence intensity us concentration of silver: Average standard deviation: $S=1.36 \% \mathrm{Ag}$

placement of the basic absorption lines and absorption edges for $\mathrm{Ag}, \mathrm{Pd}$ and $\mathrm{Au}$, as indicated in Figure 3, means that for alloys with high proportions of silver and palladium, the effects of enhancement of $\operatorname{PdK} \alpha$ and $A_{u} L \alpha$ by palladium and silver lines of the $K$ series may be observed. This may be direct enhancement of, for example $A u L \alpha$ radiation by the more energetic

\section{Correction Coefficients}

$\begin{array}{cc}\beta_{\mathrm{ik}} & \gamma_{\mathrm{imn}} \\ \text { elements 'k' } & \text { elements 'm, } \mathbf{n}^{\prime} \\ \mathrm{Ag}, \mathrm{Pd} & \mathrm{Ag} \rightarrow \mathrm{Pd} \\ - & - \\ \mathrm{Ag} & - \\ - & - \\ - & -\end{array}$

$\mathrm{PdK} \alpha$ radiation; or indirect enhancement, for example, of $\mathrm{AuL} \alpha$ radiation by $\mathrm{PdK} \alpha$ radiation which has been additionally enhanced by $\mathrm{AgK} \beta$ radiation. Matrix effects became apparent whilst measuring the reference materials with the PW1404 Philips X-ray Spectrometer equipped with a $\mathrm{Mo} / \mathrm{Sc} \mathrm{X}$-ray tube. The analytical parameters for the Spectrometer are given in Table 3.

The least squares method was used to determine the relationships between the concentration of the elements in the standards and the corresponding $\mathrm{X}$-ray intensities. These are shown in Figures 4 and 5 for gold and silver. The residual standard deviations obtained were \pm 4.82 for gold and \pm 1.36 for silver and these indicate strong absorption enhancement effects, disturbing the linear relationships between concentrations and XRF intensities for these elements. The values for the other elements of interest for jewellery alloys are also large: palladium $\pm 0.87 \%$, copper $\pm 0.56 \%, \mathrm{Zn} \pm 0.10 \%$, $\mathrm{Ni} \pm 0.65 \%$, making their acceptance for quantitative analysis purposes impossible.

It is therefore necessary to apply corrections for these absorption enhancement effects (both direct and indirect) and the Philips model was used. This is a combination of the Claisse-Quintin (5), de Jongh (6), Lucas-Tooth-Pyne (7) and Rasberry-Heinrich (8) models and covers corrections for all the effects indicated above.

The model selected has the following mathematical form:

$$
C_{i}=D_{i}+E_{i} I_{i}\left[1+\sum_{j} \alpha_{i j} I_{j}+\sum_{k} \beta_{i j} \frac{I_{k}}{1+C_{i}}+\sum_{m, n} \gamma_{i m n} I_{m} I_{n}\right]
$$

Where:

$E_{1}, D_{i}$ - calibration coefficients,

$I_{i}-X$-ray fluorescence radiation intensity of analyte, 'i' 
$I_{j}, I_{k}, I_{m}, I_{n}-X$-ray fluorescence radiation intensity of matrix elements ' $\mathrm{j}, \mathrm{k}, \mathrm{m}, \mathrm{n}$, ,.

$\mathrm{C}_{\mathrm{i}}$ - concentration of the analyte,

$\alpha_{i j}$ - absorption correction coefficient,

$\beta_{\mathrm{ik}}$ - direct enhancement correction coefficient,

$\gamma_{\mathrm{imn}}$ - indirect enhancement correction coefficient. The $\alpha, \beta, \gamma$ coefficients calculated using the least squares method and ensuring optimum correction of matrix for all the determined elements are given in Table 4.

As can be seen from Table 4, the absorption effects were the dominant ones which needed to be corrected. It is necessary to take enhancement effects into account only for silver and gold - direct in both cases and indirect as well for gold.

It should be emphasized that empirically determined matrix effect correction coefficients may have slightly different values depending on the type of spectrometer used, the geometry of measurement, the $\mathrm{X}$-ray tube, the excitation and $\mathrm{X}$-ray spectrum registration conditions applied and the standards and correction models (equations) available for a given software. Other correction equations may also be used but the efficiency of correction for matrix effects should be similar. The authors have therefore checked this with

Table 5 Comparison of fitting of calibration curves without and with mathematical correction of matrix effects

\begin{tabular}{ccc} 
Analyte 'i' & \multicolumn{2}{c}{ S [\%i] } \\
& without correction & with correct \\
$\mathrm{Au}$ & 4.82 & 0.07 \\
$\mathrm{Ag}$ & 1.36 & 0.15 \\
$\mathrm{Pd}$ & 0.87 & 0.05 \\
$\mathrm{Zn}$ & 0.10 & 0.04 \\
$\mathrm{Cu}$ & 0.56 & 0.09 \\
$\mathrm{Ni}$ & 0.65 & 0.21
\end{tabular}

two types of X-ray spectrometer, ie the PW 1404 with molybdenum/scandium and rhodium tubes, and the PW 1480 'Unique' having a scandium tube. The determination of a relatively large number of correction coefficients was possible on an empirical basis for silver and gold thanks to the large number (16) of samples available. The average standard deviations (S) for the uncorrected and corrected relationships for analyte 'I' vs the intensity of its X-ray fluorescence radiation (shown in Table 5) confirms the efficiency of the matrix effects correction applied.

The values of the standard deviations obtained for the calibration curves after correction for matrix effects give confidence that the XRF method for analysis of gold alloys produces results which are very close to the accuracy of results obtained using chemical methods, as obtained by several laboratories (see Table 2). In order to confirm this, samples analysed by the Royal Canadian Mint were also analysed by XRF using corrected calibration curves. The reference materials contain copper as well as gold and silver but the copper content was not certified and is assumed to make up the composition to $100 \%$. The comparison of the results for the chemical and XRF analyses is given in Table 6.

The good agreement confirms the quality of the $\mathrm{XRF}$ results obtained using the mathematical correction for matrix effects. The variations between chemical and $\mathrm{XRF}$ analysis are between 0.01 and $0.07 \%$.

\section{CONCLUSIONS}

A series of sixteen certified gold and gold alloy reference materials has been developed. These contain between 33.32 and $99.99 \%$ gold ( $8-24$ carat) and silver, copper, palladium, zinc and nickel as alloying elements. This composition range covers those used for conventional coloured and white carat gold jewellery alloys.

The methods of production were carefully controlled to ensure that the compositions obtained

Table 6 Comparison of the results of chemical analysis (certified) with results of $X$-ray fluorescence analysis

\begin{tabular}{|c|c|c|c|}
\hline Sample & $\%$ & $\mathrm{Au}$ & \\
\hline No & Chemical & & X-ray \\
\hline BM1 & 94.847 & & 94.82 \\
\hline BM2 & 89.928 & & 89.98 \\
\hline BM3 & 84.905 & & 84.85 \\
\hline BM4 & 79.962 & & 79.99 \\
\hline BM5 & 74.988 & & 74.98 \\
\hline
\end{tabular}

$\begin{array}{lcc}\text { X-ray } & \text { Chemical } & \text { X-ray } \\ 94.82 & 4.15 & 4.08 \\ 89.98 & 8.03 & 8.02 \\ 84.85 & 12.08 & 12.13 \\ 79.99 & 15.09 & 15.11 \\ 74.98 & 15.04 & 14.99\end{array}$


accurately reflected those intended, with high homogeneity for all components.

The XRF method developed, with mathematical correction for matrix effects, enables the analysis of various grades of gold alloys using analytical curves for each element determined.

There were ten laboratories participating in the certification process, which included the use of a wide range of analytical procedures and produced good convergence. The accuracy of determination for the precious metals (gold, silver and palladium) was $\pm 0.002- \pm 0.09 \%$, and for the other elements (copper, zinc and nickel) $\pm 0.01- \pm 0.10 \%$.

The accuracies obtained for each individual element, $i e \pm 0.07 \%$ for $\mathrm{Au}$ in the range $33-100 \% \mathrm{Au}, \pm 0.15 \%$ for $\mathrm{Ag}$ in the range $0-67 \% \mathrm{Ag}, \pm 0.05 \%$ for $\mathrm{Pd}$ in the range $0-32 \% \mathrm{Pd}, \pm 0.04 \%$ for $\mathrm{Zn}$ in the range $0-8 \%$ $\mathrm{Zn}, \pm 0.09 \% \mathrm{Cu}$ in the range $0-24 \% \mathrm{Cu}$, and $\pm 0.21 \%$ $\mathrm{Ni}$ in the range $0-32 \% \mathrm{Ni}$, are in the ranges obtained for commonly applied chemical methods, but the time used for XRF analysis can be very much shorter.

\section{ACKNOWLEDGEMENTS}

The authors express their gratitude to Mrs Giovanna Valente of the Royal Canadian Mint for access to the gold bullion reference materials and valuable comments.

The reference materials are commercially available from $\mathrm{Mr}$ Janusz Luboinski, Polish State Mint, 00-958, ul Pereca 21. Tel: +4822 656 4271; Fax: +48226205522 .

\section{ABOUT THE AUTHORS}

Wieslaw Stankiewicz received his MSc from Adam Mickiewicz University in Poznan in 1969 and a PhD in 1983 from the Silesian University in Katowice.
Since 1969 he has been employed in the Analytical Chemistry Department of the Institute of Non-Ferrous Metals in Gliwice, Poland and has developed a speciality in the use of XRF spectroscopy for the determination of elements, including the precious metals, in non-ferrous metallic materials. He has also been involved in the development of reference materials for XRF spectroscopy.

Barbara Bolibrzuch graduated from the University of Wroclaw (MSc) in 1979 and is now the optical emission (OES) specialist in the same Department in Gliwice. She has recently been involved in the definition of reference materials (in co-operation with NIST, USA) for non-ferrous metals and their alloys, as well as in the development of OES methods for the determination of precious metals in various materials.

Milosz Marczak graduated from Warsaw Technical University in 1983 and he is at present deputy manager of the Chemical Laboratory at the Polish State Mint in Warsaw. He has specialized in the analysis of precious metals, including application of OES and XRF methods. He has also been involved in the preparation of precious metal calibration samples for use in various analytical techniques.

\section{REFERENCES}

1 'Gold Reference Materials for Analysis of Gold Alloys', Gold Bull, 1996, 29, 74

2 G. Valente, 'Fine Gold Reference Materials', Royal Canadian Mint, Ottawa, April 18, 1993

3 G. Valente, 'Gold Bullion Reference Materials', Royal Canadian Mint, Ottawa, January 6. 1995

4 E. Morgan, 'Chemometrics: Experimental Design', John Wiley and Sons, Chichester, UK, 1991

5 F. Claisse and M. Quintin, Can. Spectrosc, 1967, 12, 129

6 W.K. deJongh, X-Ray Spectrom., 1973, 2, 151

7 H.J. Lucas-Tooth and E.C. Pyne, Adv. X-Rav Anal., 1964, 7, 523

8 S.D. Rasberry and K.F.J. Heinrich, Anal. Chem., 1974, 46, 81 